\title{
Dogmática neoliberal y misterio de Dios
}

\section{Jesús Martínez Gordo, Facultad de Teología de Vitoria-Gasteiz.}

Analizar la relación entre el neoliberalismo y el misterio de Dios puede sorprender y hasta parecer un asunto tomado por los pelos. Más de uno puede pensar que se anda buscando llamar la atención sobre una cuestión con poco o nulo fundamento. ¿,Qué tiene que ver el misterio de Dios con el neoliberalismo y, particularmente, con su capitalismo democrático?

Quien se formula esta pregunta, lo hace, muy probablemente, a la sombra de las consideraciones de I. Kant, uno de los padres de la ilustración idealista, sobre el misterio de la Trinidad hace ya un par de siglos: "Del dogma de la Trinidad, tomado al pie de la letra - decía el pensador de Könisberg - no se podría deducir absolutamente nada para la praxis, incluso en el caso de que alguien creyera que lo entiende, y mucho menos si uno se da cuenta de que supera todos nuestros conceptos. Que tengamos que honrar a tres o a diez personas en la divinidad, el novicio lo aceptará - porque se lo dicen - con toda facilidad, ya que él no tiene ninguna idea de un Dios en varias personas (hipóstasis), o mejor aún, porque no puede sacar de esta diferencia algunas reglas distintas para su conducta" ${ }^{\text {. }}$.

Teniendo presente la concepción que una parte de la modernidad idealista tiene del misterio de Dios, no hay que extrañarse de que pretender mostrar la relación entre dicho misterio y el neoliberalismo pueda sonar a dislate y a exceso. Cada uno, se dirá, tiene que ir por su camino, sin mezclarse, ni confundirse. Y, en todo caso, mejor haría el teólogo si se ocupara de invalidar la tesis defendida por I. Kant, en el terreno veritativo marcado y olvidar esta clase de consideraciones, que no dejan de ser, en el mejor de los casos, sino simples excentricidades.

1 I. Kant, Il conflitto delle facoltà, Genova, 1953, p. 47. 
La mirada a la historia más reciente muestra, sin embargo, que la tesis kantiana - asumida por una buena parte de los ilustrados europeos - es desechada por los más importantes ideólogos norteamericanos del neoliberalismo, particularmente cuando han descubierto que algunas de las contradicciones culturales del llamado capitalismo democrático pueden ser subsanadas o, al menos paliadas, por el empleo adecuado de la religión.

Existe, por tanto, un discurso que constata y defiende la necesidad de una estrecha relación entre teología y economía. Puede que no sea un dislate indagar, por ejemplo, la relación entre el núcleo de la revelación cristiana (el misterio de la Trinidad) y el capitalismo democrático reinante.

\section{La dogmática neoliberal}

La ideología neoliberal se sostiene en tres axiomas, que han empezado a ser aceptados como evidentes e incuestionables estos últimos años, sobre todo en los países del llamado primer mundo: la búsqueda del mayor beneficio posible, la defensa de la propiedad privada de los medios de producción y la libertad de contratación y mercado.

\subsection{La búsqueda del mayor beneficio posible}

El primero y más importante de los axiomas neoliberales recuerda que "existe una y sólo una responsabilidad social en los negocios: usar sus recursos empleándolos en actividades destinadas a aumentar sus beneficios" ${ }^{2}$.

Algunos críticos han recordado que la búsqueda del mayor beneficio posible descuida, inexorablemente, las necesidades sociales de numerosos colectivos: el "proceso económico de la nueva división internacional del trabajo se desarrolla en el marco de la evolución del sistema capitalista mundial, sin tomar en consideración las necesidades sociales de las poblaciones afectadas"3.

Los ideólogos neoliberales reaccionan reconociendo tal efecto perverso, pero indicando, a continuación, que es el único mecanismo que permite generar riqueza y, por tanto, el único que abre las puertas para participar en la mesa de la abundancia, también a estas personas y colectivos sumidos en una inicial y superable postración.

Así es como se pretende obviar el mundo dual que la aplicación de tal axioma cumplimenta y justifica.

2. M. Friedman, Capitalism and Freedom, Chicago, 1962, p. 133.

3. F. Fröbel, J. Heirchs y O. Kreye, La nueva división internacional del trabajo, Madrid, 1980, p. 54. 


\subsection{La defensa de la propiedad privada de los medios de producción}

El segundo de los axiomas es la defensa de la propiedad privada de los medios de producción. Su aplicación explica la enorme concentración de poder en unas pocas manos (los monopolios y los oligopolios): la propiedad es "un artefacto cristalizador del poder" ${ }^{4}$.

Éste es un axioma socialmente muy consolidado en nuestros días, particularmente entre una buena parte de los ciudadanos del primer mundo. La experiencia comunista de una propiedad social (estatal) y el cruel autoritarismo propiciado por semejante proyecto han enfriado las consideraciones críticas en esta dirección.

Queda, sin embargo, la doctrina social de la Iglesia cuando, continuando con una tradición teológica que se remonta hasta los santos padres, establece una diferencia entre la gestión y la apropiación de los bienes. Al instituir tal diferencia, defiende la propiedad de uso y limita la privatización de los medios de producción, ya que sólo Dios es el dueño de todo. Él ha puesto esos bienes para el disfrute de todos los seres humanos y no sólo de un grupo de privilegiados. En esta consideración hunde sus raíces la moderna salvaguardia de la hipoteca social de todos los bienes, algo que los neoliberales más radicales califican como "justicialismo regresivo" 5 .

\subsection{La bondad del mercado autorregulador}

Según el tercero de los axiomas, la libertad de contratación y el mercado autorregulador son altamente beneficiosos para la humanidad, porque permiten aparcar todo lo que no sea rentable.

Es cierto, reconocen algunos neoliberales, que la coherencia con tal axioma puede resultar dura y exigente a corto y medio plazo, pero también lo es que los beneficios finales sean siempre inestimables, incluso para los directa y negativamente afectados en un primer momento. "Yo pienso - sostenía J. Stuart Mill - que, incluso en el estado actual de la sociedad y de la industria, toda restricción de la competencia es un mal y toda extensión de ella, aun cuando por algún tiempo perjudique a alguna clase de trabajadores, es siempre un bien definitivo"6.

4. R. Jeffrey Lustig, "Libertad, corporaciones y el nuevo liberalismo", en Baumann F. E., (comp.), ¿Qué es el capitalismo democrático? Esclarecedores ensayos para una definición de este polémico tema, Barcelona, 1988, p. 149; cfr ibíd., pp. 148 y ss.

5. Cfr J. Paternot y G. Veraldi, ¿Está Dios contra la economía? Carta a Juan Pablo II, Barcelona, 1991, p. 59.

6. J. Stuart Mill, Principles of Political Economy, Libro IV, Cap. VII, par. 7. En la edición de Sir William Ashley, p. 793. 
Los críticos indican que la libertad de contratación y la apología del mercado autorregulador sin los correctivos de una intervención pública son algo utópico, ya que, si bien es cierto que permiten canalizar, en un primer momento, algunas necesidades humanas, no es menos cierto que - al no estar basados en el interés general- conducen a olvidarse, por ejemplo, de la redistribución de la riqueza, del medio ambiente, del uso racional de los recursos energéticos, de la investigación fundamental y de la equidad?

Algunos ideólogos neoliberales asocian el axioma mencionado a esta otra tesis: allí donde hay libertad de mercado, florece y se consolida el sistema democrático. Sin embargo, semejante afirmación es objeto de algunas cautelas. P. Berger sostiene que "bajo las circunstancias modernas, el capitalismo es una con-

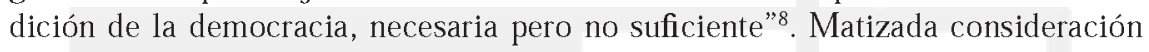
en la que aletea una crítica, tan incontestable como evidente: el proceso seguido, por ejemplo, en "Oriente Asiático ofrece un débil apoyo a la proposición de que el éxito del desarrollo capitalista genera presiones a favor de la democracia".

\section{Socialización y drama de la dogmática neoliberal}

Tres son las consecuencias más reseñables del triunfo de estos axiomas neoliberales: la generación y consolidación de un mundo dual, en el cual sus dos terceras partes luchan por la subsistencia, mientras el tercio restante demanda una mejor calidad de vida; la socialización de un código ético sometido a los intereses neoliberales y la instrumentalización de la religión. Cuando esto último no es posible, cede el paso a una estrategia de privatización de la religión o de denigración, para hacerla socialmente irrelevante.

\subsection{Un mundo dual y darvinista: vida "versus" calidad de vida}

Una sociedad construida sobre los axiomas neoliberales arroja - cuando, como es el caso, sólo se internacionaliza la economía-, un nuevo orden (?) mundial, en el cual unos pocos países y personas (los mejor preparados y equipados, básicamente los del llamado primer mundo y los detentadores del poder económico), viven en la abundancia y en el despilfarro, mientras que la gran mayoría (normalmente los países del tercer mundo y quienes no pueden acceder a capital

7. Cfr. Polanyi, La gran transformación crítica del liberalismo económico, Madrid, 1989, pp. 232.239. Cfr ibíd., pp. 255-257, 259, 389-391, 397, 399-400, 401. Cfr A. King y B. Schneider, Informe al Club de Roma. La primera revolución mundial, Barcelona, 1991, pp. 32-33, 66, 189, 239. Cf. J. Travé, "El debate por una Europa solidaria: ¿cómo se plantea actualmente?", en C. Comas, Europa: los idealismos y el talante postmoderno en Europa. Posibilidades y dificultades para la solidaridad, Barcelona 1991. p. 65.

8. P. L. Berger, La revolución capitalista. Cincuenta proposiciones sobre la prosperidad, la igualdad y la libertad, Barcelona, 1992, p. 255. (Proposición n ${ }^{0} 16$. Cfr ibíd., 18 y 19).

9. Ibíd., p. 258. 
alguno, en el interior del sistema), malviven y tienen enormes problemas para poder subsistir.

En este mundo dual coexisten dos tipos de países y, sobre todo, de personas con rostros y porcentajes yuxtapuestos, a la vez que complementarios, según cual sea el punto de vista que se adopte: local o global.

Si se analiza el primer mundo, sin relación con el resto, entonces se dibuja una sociedad en la cual dos tercios luchan por acrecentar su calidad de vida y un tercio - catalogado como cuarto mundo- busca subsistir en su interior. En cambio, si se estudia toda la aldea global, entonces las cifras quedan dramáticamente alteradas y subvertidas: la mayoría de los países y los humanos (dos tercios) lucha por la subsistencia, y es un tercio el que defiende con uñas y dientes su calidad de vida, en el primero de los mundos.

Existe, además, una indudable relación de causa y efecto entre estos mundos tan diferenciados por sus objetivos y expectativas: la calidad de vida, típica del primer mundo, sólo puede sostenerse, y hasta incrementarse, a costa de una deficiente subsistencia en los países del tercer mundo. Sobran estudios que profundizan y reafirman esta conclusión cuando analizan, por ejemplo, el consumo de los países del primer mundo y la imposibilidad de universalizar dicho nivel de consumo, por el riesgo de agotar el planeta.

Semejante constatación, y la relación de causalidad reseñada, permiten concluir — con la ayuda, en esta ocasión, de los obispos del País Vasco- que "la calidad de vida del primer mundo progresa, en gran medida, a costa del subdesarrollo, la miseria y el hambre en el tercer mundo" 10 .

No es de extrañar que Cristianisme i Justicia pronosticara en 1985 algo que, por desgracia, se ha convertido en una dolorosa realidad veinte años después: "la tensión continuará creciendo entre los países ricos y los países pobres, entre el Norte y el Sur, mientras que la injusticia y la humillación que engendra se irán tornando especial y crecientemente insoportables para los países árabe-musulmanes"11.

Los ideólogos neoliberales justifican la existencia de esta inhumana dualidad defendiendo que es la única vía para ir sacando - poco a poco e indirectamente- a los pobres de su situación. La dualidad es inevitable, aunque no insuperable. "Éste es el callejón sin salida del igualitarismo: para ayudar a las clases pobres y medias hay que disminuir los tipos de impuestos que afectan a los ricos".

10. Al servicio de una vida más humana. Carta pastoral de los obispos de Pamplona y Tudela, Bilbao, San Sebastián y Vitoria, Cuaresma-Pascua 1992, n. 44.

11. Cristianisme i Justicia, Retos para un año nuevo. A modo de decálogo, Barcelona, 1985, p. 18. 
Sólo así se evitará asustar al capital y se le permitirá crear riqueza ${ }^{12}$. O dicho todavía con más rudeza: "Lo único social es la prosperidad. Cuando un sistema tiene éxito, todos se benefician" ${ }^{13}$.

No faltan voces tan poco sospechosas de incurrir en supuestas veleidades izquierdistas (como la de los informes del Club de Roma) que niegan este principio neo-conservador, calificándolo de "mito": no "existe prueba alguna de que el crecimiento en el Norte conduzca al desarrollo en el Sur"14.

Cuando se contempla el mundo desde el punto de vista teológico, lo menos que se puede decir es que se está actualizando la parábola del rico epulón y del pobre Lázaro. O, lo que es todavía más duro, se está haciendo verdad la necesidad de que muera un justo (en este caso, dos tercios de inocentes) para defender la calidad de vida de una minoría. Toda una dramática actualización y justificación de la kénosis.

\subsection{Una ética sometida}

El éxito del neoliberalismo radica en la rentable distancia que establece entre irresponsabilidad ética y sanción legal, entre beneficio económico y moralidad del mismo: "la sociedad anónima es una persona jurídica que crea una distancia dentro de uno mismo entre los deberes morales y los derechos legales; y también entre uno mismo y los demás, ya que los deberes para con ellos están reducidos a la corrección legal" ${ }^{15}$. Tal distinción acaba generando una mentalidad según la cual lo legal es lo moral y favorece el parecer — hasta erigirlo en criterio incuestionable - de que el comportamiento ético consiste en el cumplimiento de la legalidad vigente, independientemente de la moralidad que pueda presentar. Se dice que si es legal ya es moral.

Las multinacionales industriales, financieras y militares - cuyo poder y capacidad de decisión escapan al control de los gobiernos democráticos- se convierten en el instrumento más poderoso y eficaz para socializar, hasta universalizar,

12. G. Gilder, Riqueza y pobreza, Madrid, 1984, p. 250.

13. J. F. Revel, Época 3. XII. 91. Cfr L. Sebastián, La gran contradicción del neo-liberalismo moderno o la sustitución del humanismo liberal por el darwinismo social, Barcelona, 1989, p. 7: la ideología neoliberal favorece, cuando se le deja funcionar sin correctivos de ninguna clase, un "darvinismo social" puro y duro que "exalta la necesidad y conveniencia para el conjunto de la sociedad (y la especie humana) de que algunos miembros de ella — los mejor dotados y capacitados para la competencia económica - tengan todas las oportunidades de triunfar y sobrevivir en el enfrentamiento de los hombres contra la naturaleza y de los hombres entre sí por mantener el control sobre los nuevos recursos creadores de riqueza".

14. A. King y B. Schneider, La primera revolución, p. 29.

15. H. C. Mansfield (H), "Las formas de libertad", en F. E. Baumann (Comp.), Qué es el capitalismo, p. 18. 
la apuesta moral indicada, defender el nuevo orden mundial resultante y acallar cualquier posible inquietud ético-social que la contradiga o cuestione, haciendo peligrar el beneficio económico que preside todo este entramado ${ }^{16}$.

La consecuencia es, frecuentemente, la quiebra de la lógica democrática y solidaria y, en definitiva, la recusación de cualquier clase de control político, que pudiera ejercerse en nombre de la libertad y soberanía de las personas y de los pueblos. Por encima de tales principios se encuentra siempre, revestido de las formas que se consideren apropiadas en cada época histórica, el sacrosanto beneficio. La centralidad de tal dogma explica que se derroquen y cambien autoritariamente gobiernos - en nombre, por supuesto, de la democracia - para garantizar, de paso, una pingüe cuenta de resultados económicos o, lo que es lo mismo, el control de determinados recursos.

La socialización de esta ética de la irresponsabilidad lleva a justificar una cuota de paro inevitable, propicia la economía sumergida y el trabajo precario y potencia un mundo dividido entre unos pocos cada día más enriquecidos y un tercer mundo empobrecido cada hora que pasa. A la par que se ensancha este foso, aumentan el racismo y la xenofobia hacia los emigrantes del sur, se incrementa la pobreza (asociada cada día más a la ausencia de trabajo y de un sueldo), se va condenando la solidaridad a la irrelevancia — por la progresiva interiorización de la lógica individualista del sistema - y se propicia un desprestigio de la política del bienestar. El Estado - se sostiene - es caro, ineficaz y acaba imponiéndose a los individuos ${ }^{17}$.

Nada más lejos, una vez más, del código moral que brota y se asienta en la kénosis de Dios y en su preferencia por los más pobres.

\subsection{Una religión instrumentalizada}

El neoliberalismo, reconocerá uno de sus ideólogos, "es parte de un todo, que comprende una psicologîa, una ética, e incluso una teología; y ese todo no es sombrío sino edificante" 18 . Y lo es, en buena parte, por la alianza -intere-

16. Cfr. B. R. Barbier, "Contra la economía: capitalismo o socialismo, pero ¿qué pasa a la democracia?”, en F. E. Baumann (comp.), Qué es el capitalismo, pp. 49 y ss. Ibíd., op. cit., p. 51: las multinacionales "son incompatibles con el capitalismo y el socialismo, y son altamente corrosivas de la democracia”.

17. M. Conde, "Capitalismo y ética", Vida Nueva 1840 (1992) 39. Cfr. J. Miralles, El debate del estado del bienestar, Barcelona, 1992; Cfr. R. Gómez López-Egea, "A la sombra de J. Maynard Keynes. El mito del estado del bienestar, o cómo convertir a los ciudadanos en súbditos sumisos y llevar a los países a la ruina”, Vida Nueva 1835 (1992) 23-30.

18. W. Kristol, "Los amigos y enemigos del capitalismo democrático", en F. E. Baumann. (comp.), Qué es el capitalismo, p. 72. Cfr. J. Habermas "La modernidad, un proyecto inacabado", en H. Foster, J. Habermas, J. Baudrillard et al., La postmodernidad, Barcelona, 1985, p. 25. La cultura interviene en la creación de todos estos problemas que detectan los neoconservadores "de una manera muy indirecta y mediadora". 
sada, obviamente - que establece con la religión. "Lo que necesitamos no son tantos mitos (se entiende, de corte socialistas) como creencias religiosas que - a pesar de su supuesta 'irracionalidad' - son portadoras, en sus profundidades simbólicas, de la mayor de las verdades pragmáticas e históricas: nos dicen que nada prevalecerá contra los hombres libres que tienen fe en el futuro y se comprometen con él"19. Sólo al amparo de semejante fe es posible seguir creando riqueza y distribuirla. Y sólo una fe de tal calado motiva al ser humano a defender el capitalismo democrático, entregando, si es preciso, la propia vida.

La teología de la liberación, a diferencia del neoliberalismo, se limita a ser meramente exhortativa, pre-teórica, nada práctica y cuestiona -inútilmente, por cierto - algo que la historia está evidenciando diariamente con particular contundencia: sólo la alianza de capital y cristianismo es capaz de sacar al mundo de la tiranía y del hambre, sólo la universalización del capitalismo democrático sacará al mundo de las garras de la miseria y de la opresión.

Es cierto, reconocen los ideólogos neoliberales, que el capitalismo presenta algunas contradicciones. Sin embargo, tales contradicciones son únicamente culturales (nunca estructurales) y no afectan para nada a los axiomas en los cuales se fundamenta el neoliberalismo triunfante. Y, desde luego, es posible superarlas con la ayuda inestimable de la religión. A ella toca difundir - en unión con la escuela y la familia - aquellos valores que la cultura consumista pone en riesgo de liquidación: la eficacia, la responsabilidad, la disciplina, el esfuerzo y la responsabilidad.

Son legión los teólogos y estudiosos que han criticado esta fundamentación del capitalismo democrático, recordando que su finalidad primera y última no es otra que la de legitimar religiosamente tal sistema y encubrir la situación de miseria, opresión y muerte antes de tiempo que genera.

\section{Los complejos de una izquierda europea "contaminada"}

La borrachera de libertad traída por la derrota ideológica del comunismo está llevando - también en los países europeos - a un individualismo feroz. Ello explica que la solidaridad quede reducida a políticas sociales sumamente timoratas, ocupadas en mostrar la rentabilidad — por supuesto, también económica - de un debilitado Estado de bienestar o a cuestionar con timidez el neoliberalismo imperante.

Es cierto que los progresistas europeos más sensibles a la solidaridad no ven con buenos ojos que el mundo se haya convertido en una aldea global sólo desde el punto de vista económico y que los capitales circulen sin fronteras, ni peajes de ninguna clase. Esta consideración crítica explica, en buena parte, su propuesta

19. Cfr. G. Gilder, Riqueza, p. 331. 
de gravar dichos movimientos de capitales con una tasa. Pero también es manifiesto que con frecuencia se limitan a sobrellevar, con cara compungida, que este mundo no sea también una aldea global desde el punto de vista democrático.

De hecho, gobiernan en bastantes países defendiendo con uñas y dientes las fronteras existentes, sin tener mucho interés en que dos tercios de la humanidad - mayoritariamente pobre - accedan, como mayoría, a un gobierno mundial. E1 pragmatismo también se ha apoderado de ellos. En consecuencia, se limitan a incrementar tímidamente el gasto social y a reivindicar la libertad individual con tanta o más fuerza que los neoliberales. Es el rostro "posibilista" en que fragua y se visualiza la rendición al neoliberalismo económico y político entre una buena parte de los progresistas europeos. La fascinación que en ellos ejerce la libertad individual, coexiste con frecuencia con el sacrificio de la solidaridad para con los más débiles. Y lo hace en nombre del pragmatismo.

La consecuencia es que la política económica neoliberal, la democracia formal burguesa o el llamado capitalismo democrático son incuestionables no sólo para los progresistas norteamericanos, sino también para los partidos de izquierda europeos, a los cuales sólo les queda como seña de identidad marcar distancias con respecto a determinadas confesiones, particularmente con el catolicismo y con los fundamentalismos que, de manera sorprendente, sólo son religiosos; casi nunca económicos o políticos.

Esta estrategia, por lo general, pretende ocultar, por una parte, el fundamentalismo económico en el que se asienta la tan cacareada calidad de vida del satisfecho primer mundo (a costa de la lucha por la subsistencia de las dos terceras partes de la humanidad) y, por la otra, el fundamentalismo político de las llamadas democracias formales burguesas. Este fundamentalismo político se visualiza, por ejemplo, en la defensa de las actuales fronteras políticas (no así de las económicas) y en la renuencia a propiciar un gobierno mundial, que supere la estructura medieval, en la que se desenvuelve la Organización de Naciones Unidas, en la actualidad.

Es cierto que el discurso desde los pobres y sobre los pobres suele ser atentamente escuchado, en particular por la izquierda. Pero también lo es que acaba siendo aparcado, de forma respetuosa, por su carga utópica, sobre todo, cuando se proponen reformas estructurales o cuando se demanda una articulación más cuidada con la solidaridad.

Quizá, por ello, no esté de más analizar el neoliberalismo triunfante $-\mathrm{y}$ el formalismo democrático en que viene dado - a partir de la revelación cristiana y, en particular, de lo que es su corazón: la manifestación de Dios en Jesús como Trinidad salvífica o, lo que es lo mismo, "económica". Cuando se procede a este análisis, emerge con toda su crudeza el fundamentalismo inhumano de los cimientos económicos y políticos sobre la que se está construyendo el mundo 
actual y se historiza el misterio de un Dios partidario de los sufrientes de nuestros días y de todos los tiempos. Se evidencia algo que por más contundente que pueda parecer, no deja de ser, por ello, tan incuestionable como sangrante: nos encontramos en las antípodas de lo que es la entraña misma del misterio de Dios entregado en la cruz.

\section{El misterio de Dios y la dogmática neoliberal}

Pocos ponen en duda que Dios es misterio. Que sea un misterio del que se puede hablar, es ya algo más discutible. Pero esta posibilidad es una de las líneas que marca la diferencia - al menos, en los planos discursivo y motivacional - entre creyentes y no creyentes y la que, incluso, permite adentrarse en la relación entre economía y misterio de Dios.

Es sabido que los cristianos defienden la posibilidad de hablar de ese misterio, porque Dios ha tenido a bien manifestarse y darse a conocer. Esta revelación ha acontecido en Jesús como una anticipación del final que, además, se actualiza en el tiempo presente. Gracias a Él es posible hablar del misterio de Dios, en una dirección doble y complementaria: desde la comunión diferenciada en que viven el Padre, el Hijo y el Espíritu Santo (la "Trinidad inmanente") y desde de la encarnación, crucifixión y descenso a los infiernos del Hijo (la "Trinidad económica", es decir, su presencia salvífica en la historia).

\subsection{El misterio de Dios en los primeros tiempos de la Iglesia}

Se entiende la sorpresa de las primeras comunidades cristianas (sobre todo las de extracción judía) ante la proclamación de un Dios Unitrino. Era una tesis que colisionaba de frente con su concepción monoteísta de la divinidad. Pero se explica, igualmente, la necedad que suponía anunciar a los griegos un Dios crucificado. Esto era algo que rompía un imaginario divino, asociado - en el caso del panteón helénico - no sólo a la lógica humana, sino, sobre todo, a la fuerza y a la posibilidad de alterar el curso normal de la vida.

No es de extrañar que una buena parte de las mejores cabezas de la comunidad cristiana se dedicara durante siglos a escrutar y balbucir algo sobre este misterio, en esa doble dirección, como afirmación de la singularidad de cada persona en la unidad (Trinidad inmanente). Y, también, como sorprendente entrega, que trastocaba el imaginario religioso dominante, al vincular el poder salvífico de Dios con la fragilidad de la condición humana y, sobre todo, con el fracaso de la cruz (Trinidad económica).

De todas formas, fueron las consideraciones sobre la Trinidad inmanente y sobre las naturalezas de Jesús las que llevaron más tiempo a las primeras comunidades cristianas. Como consecuencia de ello, las cuestiones relacionadas con la eclesiología, la organización política y la antropología recibieron una luz 
clarificadora: si el corazón del misterio de la Trinidad es la comunión, es lógico que sea ella la que presida las relaciones entre los cristianos y entre las comunidades (la articulación entre presidencia, colegialidad y corresponsabilidad y la comunión de bienes y personas). Y si Jesús se hace uno de los nuestros, hay que concluir que con Él no sólo se inicia una nueva manera de tratarse con Dios (lo más íntimo a mí mismo y lo más trascendente a uno mismo), sino también, y de modo particular, un proceso de dignificación ("divinización") de la persona.

Pero esas adquisiciones, siendo importantes, no lo son todo. También irrumpe con particular fuerza la concepción de la autoridad como servicio, se reconoce el protagonismo de la comunidad (un debate que recientemente se centrará en la correspondencia entre comunión y democracia formal burguesa en la "aldea global") y, sobre todo, se abre una sorprendente vía de relación con el Dios Unitrino, en la mediación de los pobres, algo desconocido hasta el presente. Ellos llegarán a ser reconocidos como los "vicarios de Cristo" (P. de Blois) y el "tesoro de la Iglesia” (S. Juan Crisóstomo).

\subsection{El misterio de Dios en la teología contemporánea}

Hubo un momento, sin embargo, en el que tocaron fondo las consideraciones sobre las naturalezas y las relaciones de las personas, en el seno de la Trinidad, y su capacidad para iluminar la existencia humana, la realidad social y la vida eclesial. Los debates de escuela, lo prolijo de los mismos y la irrupción de una cultura racional, autónoma y recelosa de cualquier revelación determinaron que las aproximaciones al misterio de Dios cayeran en una creciente insignificancia. Empezó a abrirse camino, poco a poco, un proceso que llevará a la misma negación de la existencia de Dios y a la afirmación de una vida marcada por la tragedia de la soledad y de la finitud, en el nihilismo más reciente. El comentario de I. Kant es, entre otros, un elocuente testimonio del deísmo que se va abriendo camino, que posteriormente cederá el paso al ateísmo, al antiteísmo y, en nuestros días, al nihilismo y al agnosticismo.

Pero la relación de la modernidad con el misterio de Dios no es sólo la historia de su imparable irrelevancia o de su desalojo, es también la concientización - al menos en la corriente romántica - de que dicho misterio presenta una perspectiva salvífica o redentora ("económica"), algo no debidamente tenido en cuenta hasta el presente. B. Pascal, S. Kierkegaard y F. Dostoievski, entre otros, subrayarán con particular contundencia la fortaleza salvífica del amor divino, en el fracaso de la cruz, es decir, la llamada Trinidad económica. La agonía de Jesús - sostendrá B. Pascal - se prolonga hasta el final de los tiempos. Y F. Dostoievski defenderá algo que llegará a ser una auténtica provocación en la teología y el pensamiento contemporáneos: sólo el dolor de los sufrientes y humillados tiene fuerza suficiente para redimir al mundo y vencer a la muerte. En la muerte de Jesús se asiste a la muerte de la muerte $y$, por ello, a la victoria de la vida. 
En el siglo XIX, el papado - buscando un puesto en el nuevo mapa político de Europa - acabará perdiendo de vista lo que siempre había sido el corazón del misterio trinitario (la preferencia de Dios por los pobres) y dejará en manos de otros pensadores y de otras organizaciones, formal y explícitamente no cristianos, lo que hasta entonces había sido su razón de ser. Es cierto que, a pesar de todo, también existen cristianos (tal es el caso de los socialistas religiosos) para quienes la centralidad de los crucificados contemporáneos — fundamentalmente los obreros del mundo industrializado - relativiza cualquier confesión de ateísmo explícito. $Y$ es igualmente cierto que no faltan testimonios admirables de cristianos que siguen entregando su vida en favor de los más pobres, a lo largo de este aciago siglo. Pero también lo es que la preocupación del papado por encontrar su lugar político lleva a que una buena parte de la Iglesia acabe pactando con los nuevos poderosos del mundo y, lo que es más triste, se olvide de los pobres o haga de ellos, en el mejor de los casos, objeto de solicitud meramente asistencial, sin tocar para nada la estructura que los genera. Nada más extraño al evangelio, a la predicación de los santos padres y a las aportaciones de muchos de los mejores teólogos y santos de la Iglesia. Habrá que esperar al Concilio Vaticano II y, sobre todo, a su recepción para que se recuperen unas raíces que no debieron perderse nunca.

Más allá de la incuestionable necesidad de matizar y ampliar estas constataciones, el silencio en que queda sumida la revelación en la modernidad idealista (y empirista) coexiste con una reivindicación de su capacidad salvífica y redentora en la romántica. Como consecuencia de ello, una parte importante de la teología contemporánea queda felizmente prendada por el misterio de un Dios, que manifiesta su poder redentor en la debilidad, en el fracaso histórico de la cruz, en el silencio del sábado santo y en el descenso a los infiernos. La atención al misterio de Dios como Trinidad económica permite percatarse de nuevo - y tras un largo tiempo de olvido - de la asociación, tan libre como gratuita, de Dios con los pobres de este mundo. Y pone las bases para reformular la moderna y clásica pregunta sobre el dolor (¿por qué permite Dios el dolor y la muerte de los inocentes?), en los términos propios de un tiempo postilustrado, en el cual Dios - asociado a los sufrientes y víctimas de este mundo - pregunta por nuestra responsabilidad, en semejantes atropellos.

Como se puede apreciar, el misterio del poder salvador de Dios en la derrota del Crucificado permite leer la historia con una indudable originalidad y dota de un estatuto particularmente importante a los crucificados de cualquier época, ya que en ellos se actualiza el misterio del anonadamiento divino y de la salvación. Ellos son el rostro actual del Crucificado y la redención llega de sus manos. Y, a la vez, desde ellos es posible asomarse al Dios entregado en Jesús, percibiendo aspectos del mismo no debidamente tenidos en cuenta hasta el presente. 
El misterio de Dios ya no se escruta sólo como la fuente en la cual encontrar posibles respuestas al problema del sentido de la vida y de la historia o a la organización de la Iglesia y al gobierno de la sociedad, sino, sobre todo, como luz que ilumina la cuestión - candente y actual como pocas - de un destino realmente fraterno y solidario, en un mundo que, ciertamente, se ha convertido en una aldea global, pero que sólo es global para los medios de comunicación social y para el movimiento de capital. Y, a la vez, está llevando, a una inusitada consideración del mismo misterio de Dios como amor partidario y misericordia asimétrica, en un mundo dual e injusto.

\subsection{Misterio Dios y mediaciones sociales}

Esta aproximación a Dios, desde los crucificados del mundo, lleva a revisar tanto los axiomas neoliberales imperantes en nuestros días, como el sistema económico y político que favorece dichos axiomas, los resultados que propicia y los discursos -incluidos los teológicos - que apadrina y divulga.

Así abordado, el misterio de Dios no sólo se presta como ocasión excepcional para contemplar la fragilidad histórica del amor divino sino, sobre todo, como un misterio dotado de una indudable fuerza clarificadora -incluso, hasta cegadora - ya que saca a flote los fundamentalismos en los que se sostiene el sistema neoliberal y todos los intentos de justificarlo como lógica sensata. Por de pronto, permite desenmascarar la quimera - por cierto, altamente rentable - en la que se sostienen el neoliberalismo triunfante y sus intentos por instrumentalizar la religión, poniéndola al servicio de un proyecto cainítico. Y, a la vez, el mundo que está propiciando la lógica neoliberal arroja una sorprendente luz sobre Dios: el amor trinitario es partidario, y la universalidad de su misericordia sólo es comprensible desde "el universal concreto", los crucificados de nuestros días. Esta es una verdad que - incuestionable a lo largo de toda la historia de la Iglesia, pero eclipsada durante el siglo XIX - reaparece con particular fuerza y capacidad comprensiva en nuestros días.

Pese a que estas consideraciones son tan obvias, todavía siguen siendo legión los teólogos para quienes el diálogo entre el misterio de Dios y la historia ha de establecerse sólo en referencia a la modernidad filosófica - ya sea en sus variantes idealista, empirista y romántica - o en relación con las corrientes neopositivistas, nihilistas, postmodernas y simbólicas, que nos ha traído el pensamiento contemporáneo.

Es de sobra conocido que la ilustración idealista y empírica no sólo reivindica el protagonismo de la razón frente a la revelación sino, igualmente, de la libertad (personal, de mercado y de organización política) frente a cualquier forma de autoridad que no respete la autonomía personal y la soberanía de los pueblos. Consecuentemente, el debate ha de establecerse con las demandas veritativas de una razón autónoma y con una libertad que pretende descansar sobre sí misma. 
La coherencia de este planteamiento lleva a reconocer que una de las asignaturas pendientes de la teología es, precisamente, el diálogo entre las ciencias políticas, económicas y sociales, por un lado, y la revelación del misterio de Dios, por otro. Ésta es una tarea necesaria e imprescindible, si se pretende mostrar la luz que arroja el misterio de Dios, en un mundo construido no tanto sobre el debate filosófico, cuanto sobre las decisiones políticas y económicas. Y sobre todo cuando un diálogo de semejante calado está presidido por la voluntad de alcanzar un destino realmente solidario y fraterno, incluso con quienes tienen dificultades para acoger el sentido explicitado a partir de la revelación cristiana. Hace poco, G. Gutiérrez ha recordado este dato elemental. Y lo ha hecho prolongando e historizando la preferencia tradicional de la comunidad cristiana por los pobres, a lo largo de toda la historia. En continuidad con esta aportación, hay que entender el cuidadoso estudio de J. I. González Faus sobre la centralidad de los pobres y la luz que esa verdad revelada ha ido arrojando en las diferentes épocas, en las cuales se ha ido forjando la tradición cristiana ${ }^{20}$.

La emergencia de las referencias económica y política ha puesto de manifiesto que en dichos espacios no sólo se juega el sentido de la vida y de la historia (algo a lo que han sido particularmente sensibles los diálogos entre las diferentes teologías y filosofías), sino, sobre todo, la posibilidad de un destino realmente humano y fraterno o, con lenguaje evangélico, el reino de Dios. Existe un ateísmo práctico mucho más letal para la humanidad y para el misterio de Dios que toda la increencia teórica. Frecuente y desgraciadamente es un ateísmo asumido y defendido por creyentes explícitos.

Esta es la razón por la que el diálogo entre teología, política y economía está irrumpiendo con particular fuerza. Y lo está haciendo no tanto como algo sectorial, sino - algo que es una grata novedad - como un saber inscrito en el área de lo fundamental, es decir, como una disciplina en la cual se juega el núcleo capital de la fe cristiana o, lo que es lo mismo, el misterio de Dios. No hay que extrañarse de que semejante teología se ocupe no sólo de ver la historia política y económica a la luz del misterio divino, sino también de acercarse a la revelación desde tales saberes.

Es posible que este doble viaje (del misterio de Dios a la historia y de ésta al corazón de la revelación cristiana) explique la modestia, la pluralidad y la disparidad de la emergente teología política y económica. Esto es constatable, cuando se tienen presentes - y se comparan - aportaciones tan relevantes y dispares de los últimos años como la teología kenótica ilustrada, la teología política "después de Auschwitz", la teología de la liberación "en Ayacucho" y la teología neoconservadora norteamericana.

20. Cfr. J. I. González Faus, Los vicarios de Cristo. Los pobres en la teología y espiritualidad cristianas. Antología comentada, Cristianisme i Justicia, Barcelona, $3^{\text {a }}$ ed., 2006. 


\subsection{La teología kenótica ilustrada}

Existen escuelas teológicas que - teniendo presentes los valores que propicia la Europa ilustrada y moderna - centran su atención, alternativamente, en el dolor de Dios o en los problemas de aceptación de su verdad. H. U. von Balthasar y W. Pannenberg son dos exponentes, con toda probabilidad los más importantes, de esta diferenciada perspectiva teológica, a la hora de hablar del misterio de Dios y de analizar el mundo europeo.

Dios es, en la perspectiva y en el diagnóstico de Hans Urs von Balthasar, la víctima. El dolor que preocupa al teólogo suizo es fundamentalmente el de un Dios Trinitario que - además de no ser acogido tal y como libremente se revela, sino al modo de las cortas posibilidades ilustradas - tiene que pagar el precio de padecer en su carne la victoria de la muerte y la experiencia del abandono total. La víctima es, por tanto, el Hijo de Dios en su movimiento kenótico y redentor. Por eso, el anonadamiento de Dios es un drama intradivino (un Teo-drama), al cual se suma la cortedad de miras del ilustrado europeo, tan autocéntrico como solitario. En consecuecia, el dolor humano sólo tiene una importancia derivada y colateral en su propuesta. Y, en todo caso, no pasa de ser algo provocado por la ceguera y el solipsismo típicamente ilustrados.

La víctima en la perspectiva y el diagnóstico de W. Pannenberg - y a la cual el teólogo luterano pretende acompañar - es el ilustrado europeo, que tiene que vérselas con el "viernes santo especulativo" (Hegel), desencadenado por la modernidad y por sus epígonos actuales, marcadamente relativistas y nihilistas. Es la víctima angustiada por las enormes dificultades que presenta la posibilidad de mostrar de manera convincente que la revelación y la fe cristiana no destruyen la naturaleza humana, sino que la llevan a su perfección, porque en ellas se encuentran su camino, su verdad y vida (Cfr. Jn 14,6). Y es el drama de un europeo ilustrado y relativista que se debate entre la creencia y la increencia, por razón de la supuesta inconsistencia de la revelación cristiana, en un mundo centrípeto y relativista.

\subsection{La teología política "después de Auschwitz"}

Según J. B. Metz, ya no es posible hablar del misterio de Dios sin pasar, aunque sea metodológicamente, por lo que ha supuesto la tragedia de Auschwitz a las personas de todos los tiempos, y debe suponer también a quienes - anclados acríticamente en los postulados de la modernidad - la siguen defendiendo como la propuesta más sensata y racional.

Una teología que pretenda hablar significativamente, en nuestros días, del misterio de Dios ha de recuperar la memoria y la profecía como claves fundamentales de la revelación cristiana. La memoria, en primer lugar, como memoria passionis, como recuerdo y testimonio de un sufrimiento tan inhumano e incom- 
prensible como interpelante y doliente en el presente. Y, en segundo lugar, como profecía, es decir, como denuncia y aguijón inevitablemente presente en la cruz de tantos inocentes llevados al matadero. Una profecía que llama la atención sobre las "inocencias culpables" de quienes en nuestros días, de una u otra manera, pasan de largo ante situaciones semejantes, aunque tan sólo lo sean remotamente análogas.

$Y$, de la misma manera, que no se puede hacer una teología igual antes que después de Auschwitz, tampoco se puede proponer una mística que no haya pasado por semejante tragedia. Cuando se procede a una inmersión de tal calado, se aprende a diferenciar entre la mística como simple iluminación interior y lo que el teólogo alemán denomina "mística de ojos abiertos", es decir, la relación con Dios en las víctimas de este mundo. No se encuentra a sí mismo quien se busca ensimismadamente, sino quien se pierde en los demás y, en particular, en los más pobres. En una frase lapidaria: el encuentro con los crucificados de este mundo es la condición ineludible de cualquier autocentramiento personal, que pretenda ir más allá de la mera terapia psicológica.

Esto no tiene nada que ver con la ideología neoliberal — también alojada en algunas teologías contemporáneas - que enfatiza la importancia de "salir de sî" para "ganarse a sí mismo", es decir, para volver a sí mismo y encontrar un poco de quietud, frecuentemente tan autocomplaciente como narcotizante y ciega.

Toda una nueva manera de proponer la elaboración de una nueva antropología teológica, debidamente historizada.

\subsection{La teología de la liberación "en Ayacucho"}

La teología de la liberación habla de Dios - como repite G. Gutiérrez- no en el seno de una sociedad secularizada o "después" del drama padecido en Auschwitz (por tanto, como un problema especulativo y teórico en primera instancia), sino "en" el valle de silencio, muerte y desolación que es el "Ayacucho" actual (y, por extensión, América Latina), sumido en una violencia irracional y totalmente indiscriminada.

El drama divino deja de ser - tal como lo ha presentado H. Urs von Balthasar - una tragedia en el seno de la Trinidad inmanente y cobra densidad histórica en la teología del peruano. El dolor de Dios, el poder de la muerte y del pecado se visualizan en la opresión, el abandono y el desprecio de las víctimas, generados por el actual neoliberalismo económico y la democracia burguesa que le es pareja. La Trinidad inmanente también es Trinidad redentora y salvífica (económica), históricamente significante en América Latina.

El Dios trinitario es, por consiguiente, el Dios liberador que se asocia — por pura gratuidad y libremente - a las víctimas, que genera la idolización de los axiomas sobre los que se sostienen el sistema actual y sus instituciones; y, asociándose a estas víctimas, abre la puerta a la liberación y a la justicia. 
El misterio de Dios no es para esta teología un problema teórico sino una cuestión dramática. Lo que está en juego es el significado concreto e histórico de un Dios amoroso, en medio de la muerte, algo que no sólo lleva a implicarse en las reivindicaciones políticas y económicas de las víctimas sino, también, a establecer y cuidar el diálogo entre la revelación cristiana y los saberes políticos y económicos.

Jung-Mo-Sung, F. Hinkelammert y H. Asmann, entre otros, se encargarán de dar cuerpo a esta nueva necesidad, desde la perspectiva de los parias de este mundo. Conceptos como "víctimas" o "idolatría" volverán a ocupar — continuando con una tradición secular - un puesto importante en sus discursos teológicos.

\subsection{La teología neoconservadora norteamericana}

Tampoco faltan los discursos teológicos que enfatizan la importancia de la religión, en las sociedades avanzadas del primer mundo, porque desempeñan un papel irremplazable en el sostenimiento del sistema democrático $\mathrm{y}$, sobre todo, en la generación de riqueza.

Son las teologías neoconservadoras que _ prolongando las aportaciones más relevantes de M. Weber - defienden, entre otros, P. Berger, D. Bell y M. Novack. En general, son contribuciones que dan un tratamiento instrumental a la religión, porque puede ser en nuestros días - tal como lo ha sido hasta el presente - el correctivo saludable para el consumismo, en que necesaria e inevitablemente tiene que finalizar el sistema capitalista.

El mercado, recuerdan estos ideólogos, presenta una incuestionable fractura cultural, que no puede solucionar por sí mismo. Al generar riqueza, el mercado tiene que crear necesidades con el correspondiente deseo de consumir, y también con el riesgo de que el consumidor (que es, a la vez, un trabajador) piense que ha llegado al "final de la historia". Así se puede entregar al placer, y olvidarse de lo que constituye el "alma" del sistema capitalista: trabajar, ser eficaz, responsable, austero y, en definitiva, "profesional". Compete a la religión salir al paso de esta contradicción altamente peligrosa para el capitalismo democrático, proponiendo y estimulando la asunción de dichos valores por ser los que, además, mejor sintonizan con la entraña misma de la revelación cristiana y los que evitan el derrumbe del mercado.

M. Novak va más lejos y hace una relectura teológica del capitalismo, en la cual sostiene que la economía de mercado es el nuevo siervo sufriente. No existe, sostendrá, ningún sistema que, como el capitalista, haya generado tanta riqueza y bienestar a la humanidad, y haya combatido mejor y más eficazmente la pobreza y la miseria del mundo. $\mathrm{Y}$, sin embargo, no hay institución que siga siendo tan criticada, vilipendiada y despreciada. La búsqueda de una explicación satisfactoria a semejante contradicción lo lleva a reconocer, aunque pueda parecer una provocación, que 
el capitalismo es el nuevo siervo sufriente, de cuyo dolor sólo brotan bien y abundancia para todos.

En palabras del mismo M. Novak: "durante muchos años, uno de mis textos preferidos de la Escritura fue Isaías 53, 2-3: 'Creció en su presencia como brote, como raíz en el páramo: no tenía presencia ni belleza que atrajera nuestras miradas ni aspecto que nos cautivara. Despreciado y evitado de la gente, un hombre hecho a sufrir, curtido en el dolor, al verlo se tapaba la cara; despreciado, lo tuvimos por nada'. Quisiera ampliar estas palabras a la Business Corporation"21.

Las razones de esa "ampliación" se encuentran - al decir de M. Novak - en la tesis central que preside esta teología neoliberal: el dinero es un incentivo inocente en sí mismo, que a la vez que se automultiplica es capaz de crear vínculos sociales. Su importancia es tal que de su existencia y abundancia depende la salud global de la sociedad. "Por todos estos motivos, parece equivocado suponer que el espíritu competitivo por el dinero sea el peligro espiritual más mortal para la humanidad"22.

No es de extrañar que hayan sido innumerables los comentaristas que han salido al paso de esta teología neoliberal, denunciando su simplicidad, la instrumentalización de la religión y, sobre todo, la burda blasfemia que pretende justificar.

\section{La teología global y fraterna desde Europa.}

El análisis de la teología elaborada en el sur de Europa permite concluir que durante mucho tiempo ésta ha estado mirando con el rabillo de un ojo a lo que se escribía en América Latina y, con el otro, a lo que se ofrecía desde las iglesias centroeuropeas. La consecuencia ha sido un estrabismo teológico, que ha dificultado ver y diagnosticar la situación cultural de los países de la cuenca del Mediterráneo y su realidad social (económica y política) y eclesial. El precio pagado ha sido una teología con escasa entidad, limitada a ser, en el mejor de los casos, portavoz de lo que se pensaba en uno y otro lado del Atlántico.

Ha llegado el momento de hacer una reflexión teológica que, sensible a las perspectivas en juego tanto en América Latina como en Centroeuropa, y, superando los condicionamientos de su ubicación geográfica, ponga en juego la riqueza y novedad que supone su posición mediadora entre ambas perspectivas ${ }^{23}$.

Así se justifica lo que se podría llamar "teología global y fraterna desde Europa", es decir, una teología que — sensible a las cuestiones, marcadamente

21. M. Novak y John W. Cooper (Eds.), The Corporation: a theological inquiry, AEI, Washington DC, 1981, p. 203.

22. M. Novak, El espíritu del capitalismo democrático, p. 374.

23. Crf. J. Martínez Gordo, Dios, amor asimétrico. Propuesta de teología fundamental práctica, Bilbao, 1993. 
culturales, de la teología tradicional centroeuropea- reconozca y recoja la importancia de las inquietudes sociales, económicas y políticas como lugares de encuentro y diálogo, en los que también se juega el significado del misterio de un Dios Trinidad económica, es decir, de un Dios asociado, por puro amor, a los pobres de nuestro mundo.

\subsection{Los crucificados de este mundo desde el amor de Dios}

La conclusión de lo analizado hasta ahora es difícilmente contestable: el neoliberalismo triunfante se sustenta en unos axiomas que propician un mundo dual de ricos y pobres, en el cual los deseos y demandas cada vez más cuantitativas y cualitativas de una minoría acaban por imponerse a las necesidades de supervivencia de una inmensa mayoría.

E igualmente contundente es la conclusión que arroja la lectura del momento económico, cuando se analiza desde el misterio de Dios como Trinidad económica. Es entonces cuando hay que recordar que la kénosis o abajamiento de Dios en la cruz no es sólo un dato capaz de sacar al ilustrado de su cápsula idealista (Hans Urs von Balthasar) o una verdad definitiva apta para romper cualquier otra concepción de la verdad, entendida como correspondencia o anticipación del final (W. Pannenberg). Es, sobre todo, un acontecimiento que permite ver el mundo y la historia desde la revelación de Dios y de su amor-agape en la debilidad, en el abandono de la cruz y, desde ella, en los crucificados, los pobres sobre cuya hambre y muerte subsiste y se justifica el actual sistema económico y, de manera particular, la calidad de vida de los ciudadanos del primer mundo.

El trinitario es, como se puede apreciar, un misterio tremendamente esclarecedor, que ayuda a visualizar la mentira oculta en la maraña discursiva del capitalismo democrático y que muestra, a la vez, la capacidad profética de una cruz que se actualiza en los crucificados de este mundo, una verdad igualmente frágil y clamorosa.

De todas formas, no está de más recordar que el cristiano no es un masoquista, que se recree en la contemplación de la cruz. Pero tampoco un ingenuo postmoderno, que ignore el espesor del dolor humano, de la muerte antes de tiempo y de la pobreza estructural. Sabe que ha de seguir al crucificado, porque se fía de que la última palabra va a ser, por pura gracia de Dios, la resurrección. Y ésta es algo que ya se ha anticipado en el Crucificado, es decir, en el gratuito rescate de la muerte, por parte de Dios. Por ello, el cristiano sigue al Crucificado en los crucificados que este mundo neoliberal necesita crear. Pero lo hace con la firme esperanza - anticipada en el Resucitado - de que la postración no es ni va a ser la última palabra "sobre" esta historia, aunque lo pudiera ser "en" esta historia.

Por tanto, la asociación de Dios con las víctimas y la opción preferente por los pobres no es una llamada a la resignación, sino a la liberación de los directa- 
mente afectados y al acompañamiento de los mismos, también por parte de los beneficiados del neoliberalismo triunfante. Esto es algo que siempre ha sido una evidencia en la Iglesia, desde sus primeros tiempos hasta nuestros días, pasando por los santos padres y por el lamentable eclipse del siglo XIX.

\subsection{El amor de Dios desde los crucificados de este mundo}

Aun siendo sumamente importante lo concluido hasta aquí, no es lo único que se puede sostener fundadamente. Es posible ir un poco más lejos y percatarse - cierto que con alguna audacia - de que la actual situación económica permite descubrir algo del misterio de Dios, no suficientemente tenido en cuenta hasta ahora: la Trinidad amorosa se manifiesta en los crucificados del presente como amor tanto más asimétrico y gratuito cuanto más asimétrica e injusta es la situación económica. Y que, en la medida en que la Trinidad divina es acogida en su asimétrica solidaridad, se va desplegando una manera propia de percibir la realidad, validable por su capacidad para acompañar, recordar, denunciar y transformar el dolor inmenso y creciente de las víctimas, en quienes Dios se revela como amor asimétrico. Conversión a los pobres y mistagogía (adentramiento en el misterio de Dios) van de la mano.

Dicho de otra manera: cuanto más radicalmente asimétrico, injusto y doloroso se manifiesta el mundo que construimos, tanto más asimétrico y gratuito se presenta en la historia presente el Silencio amante del Padre, la Palabra amada del Hijo y el Amor inhabitante del Espíritu. Y en la medida en la que son acogidos el Silencio amante del Padre, la Palabra amada del Hijo y el Amor inhabitante del Espíritu, en los crucificados de este mundo, se va desarrollando una manera propia de ver y percibir la realidad, irreducible a otras perspectivas socio-analíticas y económicas: "el justo conoce la causa de los débiles, el malo no tiene inteligencia para conocerla" (Prov 29, 7). Esta manera original de percibir y captar la realidad se va validando por su capacidad para recordar, acompañar, denunciar y transformar la dolorosa asimetría en que se encuentra sumido el mundo que estamos construyendo.

Por tanto, el neoliberalismo triunfante, la lógica sobre la que se sustenta y el nivel de vida en que se desenvuelve el primer mundo están atentando contra el núcleo del Evangelio y el corazón de la revelación cristiana como Trinidad amorosa y, por paradójico que pueda parecer, también están desvelando el rostro genuinamente partidario del Dios que se ha revelado como Trinidad económica, en el abajamiento del Hijo.

Ésta es, por supuesto, una conclusión que no pretende ofrecer soluciones técnicas sobre cómo salir de la situación. Expresa, y no es poco, su disconformidad radical con un sistema, con una lógica sistémica, con unas actitudes y con unos comportamientos que nacen y retroalimentan el darvinismo social imperante. Un juicio e interpretación de estas características es, cuando menos, necesario, en la medida en que deben anteceder o pueden acompañar a posibles soluciones técnicas. 
En cualquier caso, es una conclusión que se encuentra en las antípodas de lo formulado por M. Novak y otros ideólogos neoliberales, a la vez que en continuidad radical con la tradición más genuina de la Iglesia, que siempre ha considerado a los pobres como los "vicarios de Cristo".

Sorprende la ceguera de un I. Kant, demasiado ocupado en conocer cómo era posible un conocimiento "verdadero", en conformidad, por supuesto, con la capacidad cognoscitiva del ilustrado idealista. La suya es una ceguera muy común en todos los pensadores - y son legión- obsesionados por alcanzar una verdad que se ajuste a lo "dado", a lo que está "ahî", a lo que es "habitual" y, en definitiva, a "lo políticamente correcto". Son pensadores que frecuentemente se autoincapacitan para ver la realidad y la vida a partir del Crucificado Resucitado y, por tanto, a partir de la verdad final anticipada y actualizada en los crucificados de este mundo dual y neoliberal, un mundo con el cual no es posible acomodación alguna. Ni siquiera mental. 